\title{
Fracionamento a seco da gordura de frango em escala piloto
}

\author{
Ming Chih Chiu', Renato Grimaldi², Luiz Antonio Gioielli* \\ ${ }^{1}$ Departamento de Tecnologia Bioquímico-Farmacêutica, Faculdade de Ciências Farmacêuticas, Universidade de \\ São Paulo, ${ }^{2}$ Departamento de Tecnologia de Alimentos, Faculdade de Engenharia de Alimentos, Universidade \\ Estadual de Campinas
}

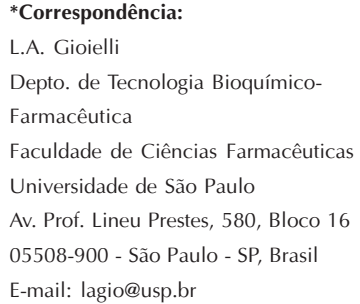

O consumo mundial de carne de frango foi de 57,8 milhões de toneladas em 2006, segundo estimativas do United States Department of Agriculture (USDA). A gordura abdominal de frango corresponde a aproximadamente 2 a 2,5\% do peso da carcaça. Os objetivos deste trabalho foram fracionar esta gordura e caracterizar as frações obtidas através da análise térmica e das propriedades fisico-químicas. A gordura de frango foi submetida ao fracionamento a seco para obter uma fração sólida à temperatura ambiente. As etapas de cristalização e filtração foram realizadas utilizando procedimentos industriais em escala piloto. As amostras foram avaliadas quanto aos pontos de amolecimento e de fusão, consistência, conteúdo de gordura sólida, composição em ácidos graxos e em triacilgliceróis, índices de iodo e saponificação, e comportamento térmico. Os resultados demonstraram que a gordura de frango é composta por $68,7 \%$ de ácidos graxos insaturados. Entre os ácidos graxos insaturados, os monoinsaturados, como o ácido oléico, são considerados desejáveis com relação à redução do risco de enfermidades cardiovasculares. O elevado ponto de fusão das estearinas em relação à gordura de frango foi devido aos maiores teores de ácidos graxos saturados nestas frações, principalmente os ácidos palmítico e esteárico. A gordura de frango e a oleína à temperatura de $10{ }^{\circ} \mathrm{C}$ apresentaram-se plásticas e espalháveis. O alto rendimento das oleínas sugere a possibilidade de aplicação destas frações como óleo para frituras e na síntese de lipídios estruturados. As estearinas podem ser utilizadas como componentes na fabricação de gorduras para aplicação em margarinas para pastelaria, massas folhadas e gorduras para bolos e sorvetes.
Unitermos

- Gordura abdominal de frango

- Estearinas

- Oleínas

- Fracionamento

- Alimentos 


\section{INTRODUÇÃO}

Desde 2004 o Brasil assumiu a posição de maior exportador mundial de frangos. Este setor consolidou-se como o segundo maior no ranking da exportação do agronegócio brasileiro. As condições de clima e meio-ambiente no Brasil são ideais para a criação de frangos. As principais matérias-primas necessárias à alimentação de aves, como o milho e a soja, são produzidas em quantidade suficiente em solo brasileiro (Abef, 2006).

O setor avícola continua a crescer em nível mundial. O Brasil produziu 9,2 milhões de toneladas de carne de frango em 2005. Deste total, 6,5 milhões de toneladas foram destinadas ao abastecimento interno. O consumo per capita anual foi de $35,5 \mathrm{~kg}$. As exportações em 2005 atingiram 2,8 milhões de toneladas de carnes in natura (frangos inteiros e cortes), além de 84 mil toneladas de produtos processados de frango, somando uma receita cambial de US $\$ 3,5$ bilhões. Atualmente, 142 países consomem a carne de frango produzida no Brasil (Abef, 2006; Apa, 2006).

O crescimento na produção de carne de aves é acompanhado por maior diversificação de produtos, com maior elaboração de itens de conveniência, praticidade e valor agregado, em detrimento da comercialização de carcaças inteiras e/ou cortes. Esta tendência ocorre em razão da mudança de hábitos da população, já que a praticidade, conveniência, qualidade nutritiva e segurança alimentar, com preços acessíveis, são condições básicas para os negócios na área de alimentação. Sob este aspecto, a carne de frango tem vantagens, pois além de apresentar as referidas características, não sofre restrições religiosas ou culturais (Olivo, 2004; Arnaud et al., 2004).

A gordura de frango pode ser incorporada em produtos de delicatessen com carnes. Ela apresenta substancial valor nutritivo devido ao seu elevado conteúdo em ácidos graxos insaturados. De acordo com Lee, Foglia (2000a,b) a gordura de frango contém cerca de $60 \%$ de ácidos graxos insaturados, sendo, portanto, altamente insaturada quando comparada ao sebo bovino. Entre os ácidos graxos insaturados, os monoinsaturados (AGMI), tais como o ácido oléico, são considerados desejáveis no que tange à prevenção de riscos de enfermidades cardiovasculares. A gordura de frango é considerada uma fonte de AGMI, uma vez que apresenta teores em torno de 45 a 50\%. Os AGMI são conhecidos como redutores dos níveis de colesterol sérico em indivíduos não-hipertrigliceridêmicos. Devido à importância destes ácidos graxos, tem sido recomendado que sua ingestão seja correspondente à metade do total de calorias ingeridas a partir das gorduras na dieta (Lee, Foglia, 2000a).

De acordo com Chiu, Gioielli, Sotero Solis (2002), para algumas matérias-primas, em especial a gordura de frango, torna-se conveniente modificar o conteúdo em frações de baixos pontos de fusão, de modo a melhorar seu comportamento térmico. Para isso, o fracionamento térmico controlado ou uma hidrogenação adicional podem ser utilizados a fim de obter frações mais duras que permitam manter as características organolépticas sem influenciar negativamente a estabilidade frente à variação de temperatura.

O fracionamento a seco é apenas uma da série de técnicas de separação que estão baseadas principalmente na propriedade dos óleos e gorduras de formar cristais. Este tipo de fracionamento é o processo mais simples e barato de cristalização fracionada, sendo conhecido como tecnologia "natural" (aquela que não utiliza produtos químicos, não produz efluentes e não tem perdas). Ao contrário de processos tais como a hidrogenação, a interesterificação e o fracionamento por solvente ou detergente, $\mathrm{o}$ fracionamento a seco não utiliza composto químico adicional. Ele consiste simplesmente na cristalização controlada da gordura fundida, conduzida de acordo com um resfriamento específico. A gordura cristalizada é, então, filtrada, dando origem às frações denominadas estearinas e oleínas (Timms, 2005; Arnaud et al., 2004; Gibon, Tirtiaux, 2002).

O objetivo deste estudo foi avaliar o processo de fracionamento a seco da gordura abdominal de frango em escala piloto utilizando técnica que poderia ser aplicada em condições industriais, com controle eficiente da cristalização e procedimento de separação das frações lipídicas.

\section{MATERIAL E MÉTODOS}

\section{Matéria-prima}

A gordura de frango foi obtida após fusão da gordura abdominal à temperatura de $90-100{ }^{\circ} \mathrm{C}$, eliminando colágenos através de filtração e a fração líquida através da decantação. A seguir, $2 \mathrm{~kg}$ da amostra de gordura foram colocados em recipientes de vidro e armazenados a temperatura de $-20{ }^{\circ} \mathrm{C}$.

\section{Processo de fracionamento a seco da gordura de frango em escala piloto}

O fracionamento foi realizado dentro de um tanque encamisado de $2 \mathrm{~L}$ provido de agitação e conectado a um controlador de temperatura com circulação de água visando o aquecimento e resfriamento da gordura. A quantidade de gordura colocada no tanque foi $1,8 \mathrm{~kg}$. Os parâmetros utilizados para esta curva foram: fusão da gordura a $70^{\circ} \mathrm{C}$ 
e sua permanência a esta temperatura durante 15 minutos, para garantir a completa fusão de qualquer núcleo cristalino. A amostra foi resfriada a uma taxa de $3^{\circ} \mathrm{C} / \mathrm{h}$ até atingir a temperatura de $20^{\circ} \mathrm{C}$. O tempo de permanência neste processo foi de 16 horas até atingir $20^{\circ} \mathrm{C}$ e a amostra permaneceu 8 horas nesta mesma temperatura. Nesta fase ocorreu a formação dos núcleos cristalinos e a permanência da gordura nesta temperatura $\left(20^{\circ} \mathrm{C}\right)$ proporcionou o crescimento dos cristais. A agitação foi realizada com agitador/raspador pneumático a velocidade de 10 a $20 \mathrm{rpm}$. Finalmente, numa terceira etapa, depois de concluído o processo de cristalização, a oleína foi separada da estearina por filtração sob pressão reduzida. Em seguida, a oleína e a estearina foram pesadas para avaliação do rendimento (Figura 1).

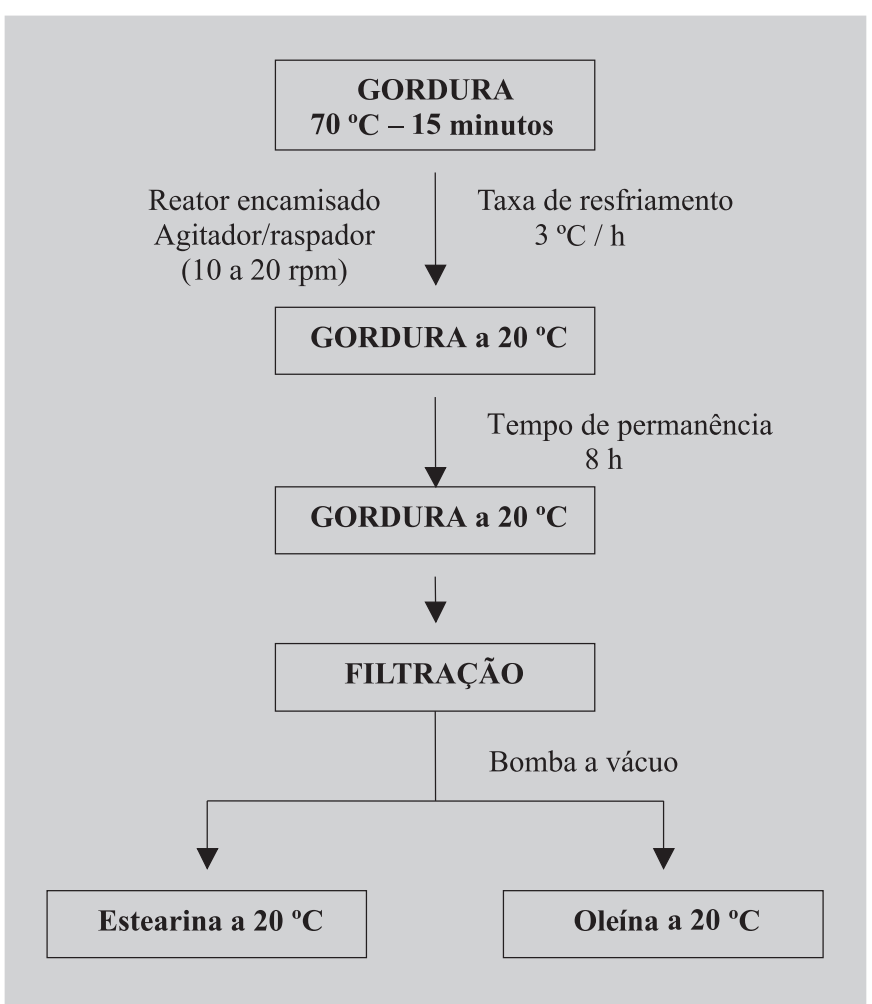

FIGURA 1 - Fluxograma de fracionamento a seco da gordura abdominal de frango.

\section{Composição em ácidos graxos}

A composição em ácidos graxos das gorduras foi determinada por cromatografia em fase gasosa, segundo normas da American Oil Chemists' Society (1998), método Ce 1-62. Foi empregado cromatógrafo a gás Varian GC, modelo $3400 \mathrm{CX}$, equipado com detector de ionização de chama e "Workstation Star Chromatography". Foi utilizada coluna capilar de sílica fundida CP WAX 52 CB
(Chrompack), com $30 \mathrm{~m}$ de comprimento e $0,25 \mathrm{~mm}$ de diâmetro interno, contendo $0,25 \mu \mathrm{m}$ de polietilenoglicol. As condições foram: razão de divisão da amostra no injetor 50:1; temperatura da coluna: $150^{\circ} \mathrm{C}$ por 5 minutos, programada até $215^{\circ} \mathrm{C}$ numa razão de $3{ }^{\circ} \mathrm{C} / \mathrm{min}$; gás de arraste: hélio, numa vazão de $1,5 \mathrm{~mL}$ por minuto; gás make-up: hélio a $30 \mathrm{~mL}$ por minuto; temperatura do injetor: $250^{\circ} \mathrm{C}$; temperatura do detector: $280^{\circ} \mathrm{C}$. A composição qualitativa foi determinada por comparação dos tempos de retenção dos picos com os dos respectivos padrões de ácidos graxos. A composição quantitativa foi realizada por normalização de área, sendo expressa como porcentagem em massa. Os ésteres metílicos de ácidos graxos para a análise foram obtidos de acordo com o método descrito por Hartman e Lago (1973). As análises foram feitas em duplicata.

\section{Índice de lodo}

O índice de iodo das amostras foi calculado a partir da composição em ácidos graxos segundos as normas da American Oil Chemists' Society (1998), método Cd 1c-85.

\section{Índice de Saponificação}

O índice de saponificação das amostras foi calculado a partir da composição em ácidos graxos segundos as normas da American Oil Chemists' Society (1998), método Cd 3a-94.

\section{Ponto de Amolecimento}

O ponto de amolecimento das amostras foi determinado pelo método do tubo capilar aberto, imerso em água sob agitação e aquecimento, de acordo com o método oficial Cc 3-25 da American Oil Chemists' Society (1998). As amostras foram analisadas em triplicata.

\section{Ponto de Fusão}

O ponto de fusão das amostras foi determinado pelo método do tubo capilar fechado, imerso em água sob agitação e aquecimento, de acordo com o método oficial Cc 125 da American Oil Chemists' Society (1998). As amostras foram analisadas em triplicata.

\section{Textura}

As análises de textura das amostras de gordura foram realizadas utilizando o equipamento analisador de textura TA-XT2, fabricado pela SMS (Stable Micro Systems), controlado pelo programa Texture Expert. As 
amostras foram aquecidas à temperatura de $60-70{ }^{\circ} \mathrm{C}$ em forno de microondas para completa fusão dos cristais e acondicionadas em béqueres de $50 \mathrm{~mL}$. O condicionamento das amostras foi efetuado durante 24 horas em geladeira comum $\left(5-8{ }^{\circ} \mathrm{C}\right)$ para cristalização da gordura e, posteriormente, durante 24 horas em estufa a temperatura controlada (temperatura de análise $\pm 0,5^{\circ} \mathrm{C}$ ). Todas as amostras foram analisadas às temperaturas de $10 \mathrm{a} 35^{\circ} \mathrm{C}$, em intervalos de $5{ }^{\circ} \mathrm{C}$. Foi utilizado cone de acrílico com ponta não truncada e ângulo de $45^{\circ}$. Os testes foram realizados em triplicata nas seguintes condições:

- Retorno ao início;

- Distância $=10 \mathrm{~mm}$;

- Velocidade $=2 \mathrm{~mm} / \mathrm{s}$;

- $\quad$ Tempo $=5 \mathrm{~s}$;

- Determinação da força em compressão (gf);

- Triplicata: 1 compressão em cada um dos três béqueres contendo amostras de gordura (Rodrigues et al., 2004; Chiu, Gioielli, 2002a).

As amostras foram analisadas quanto à consistência ("yield value"). Para o cálculo do "yield value" foi utilizada a seguinte equação, proposta por Haighton (1959):

$$
C=K \frac{W}{p^{1,6}}
$$

Onde:

$\mathrm{C}=$ "yield value" $\left(\mathrm{gf} / \mathrm{cm}^{2}\right)$;

$\mathrm{K}=$ fator que depende do ângulo do cone;

$\mathrm{W}=$ força em compressão (gf), para tempo de $5 \mathrm{~s}$;

$\mathrm{p}=$ profundidade de penetração $(\mathrm{mm} / 10)$.

\section{Conteúdo de gordura sólida}

O conteúdo de gordura sólida das amostras foi realizado segundo as normas da American Oil Chemists' Society (1998), método Cd 16b-93. Foi utilizado o método direto, sendo que as leituras das amostras foram feitas em série às temperaturas de $10,15,20,25,30,35,40,45$ e $50{ }^{\circ} \mathrm{C}$. O equipamento utilizado foi o Espectrômetro de Ressonância Nuclear Magnética Maran Ultra Bench Top, de $20 \mathrm{MHz}$.

\section{Análise Térmica}

A análise térmica das amostras foi realizada segundo as normas da American Oil Chemists' Society (1998) por calorimetria diferencial de varredura (DSC) conforme o método AOCS Cj 1-94 (1998). O equipamento utilizado foi o analisador térmico DSC 7 da Perkin Elmer acoplado ao Thermal Analysis Controller Cooler TAC 7/DX. O sistema de manuseio de dados utilizado foi o Software Pyris Series Thermal Analysis System. As condições de análise foram:

- $\quad$ Peso da amostra: $10 \mathrm{mg}$;

- Curvas de fusão: $10 \min \left(80^{\circ} \mathrm{C}\right), 80{ }^{\circ} \mathrm{C}$ a $-40{ }^{\circ} \mathrm{C}$ $\left(10^{\circ} \mathrm{C} / \mathrm{min}\right) ; 30 \mathrm{~min}$ a $-40^{\circ} \mathrm{C} ;-40^{\circ} \mathrm{Ca} 80^{\circ} \mathrm{C}\left(5^{\circ} \mathrm{C} / \mathrm{min}\right)$.

\section{Composição em triacilgliceróis}

A análise da composição em triacilgliceróis foi realizada em cromatógrafo gasoso capilar "CGC AGILENT 6850 SERIES GC SYSTEM”. Foi utilizada coluna capilar DB-17HT AGILENT (50\%-Phenyl)-methylpolysiloxane, com 15 metros de comprimento x 0,25 mm de diâmetro interno e contendo $0,15 \mu \mathrm{m}$ de filme. As condições foram: injeção split, razão de 1:30; temperatura da coluna: $250^{\circ} \mathrm{C}$, programada até $350^{\circ} \mathrm{C}$ numa razão de $5^{\circ} \mathrm{C}$ por minuto; gás de arraste: hélio, numa vazão de $1,0 \mathrm{~mL}$ por minuto; temperatura do injetor: $360{ }^{\circ} \mathrm{C}$; temperatura do detector: $375^{\circ} \mathrm{C}$; volume injetado: $1,0 \mu \mathrm{L}$.

\section{RESULTADOS E DISCUSSÃO}

\section{Rendimento das frações}

A gordura de frango apresenta tendência natural para formar cristais de tamanho grande, facilitando o processo de separação através da membrana de filtros (Gibon, Tirtiaux, 2002).

A Tabela I apresenta os rendimentos das frações estearina e oleína obtidas a partir da gordura de frango, por meio do fracionamento a seco com programação de temperatura de resfriamento. Os resultados obtidos para o rendimento da fração estearina foram cerca de duas vezes superiores aos encontrados por Chiu, Gioielli, Sotero Solis (2002) para a mesma gordura $(9,6 \%$ de rendimento para a estearina a $20^{\circ} \mathrm{C}$ ). Desta forma, observou-se que o método de fracionamento com programação de temperatura e agitação mostrou-se mais eficaz que o fracionamento isotérmico e estático. Arnaud et al. (2004) pesquisaram o método de fracionamento a seco da gordura de frango com

TABELA I - Rendimentos das frações estearina e oleína obtidas pelo fracionamento da gordura de frango a $20{ }^{\circ} \mathrm{C}$

\begin{tabular}{lc}
\hline Amostras & Rendimento (\%)* \\
\hline Estearina & 16,5 \\
Oleína & 83,5 \\
\hline
\end{tabular}

*Valores médios de processamento 
programação de temperatura, com temperatura final de $13,5^{\circ} \mathrm{C}$. Estes autores obtiveram rendimentos de $18 \%$ para a estearina e $82 \%$ para a oleína.

\section{Composição em ácidos graxos, pontos de amolecimento e de fusão, e índices de iodo e saponificação}

A Tabela II apresenta a composição em ácidos graxos, os pontos de amolecimento e fusão e os índices de iodo e saponificação da gordura de frango e das frações estearina e oleína obtidas por meio do processo de fracionamento a seco com programação de temperatura de resfriamento. Estes resultados exprimem a média de duas determinações. Observou-se que o ácido oléico é o principal ácido graxo presente na gordura de frango, representando $43,4 \%$ do conteúdo total, característica comum às gorduras de origem animal. O ácido palmítico é o principal ácido graxo saturado presente nesta gordura. Ela apresenta baixo teor de ácido esteárico quando comparada a outras gorduras animais $(6 \%$ contra $11 \%$ do toucinho e $28 \%$ do sebo bovino) (Chiu, Gioielli, 2002a; Marikkar et al., 2003).

De modo geral, os resultados encontrados para a composição em ácidos graxos da gordura de frango, sua estearina e oleína estão de acordo com os limites citados na literatura (Bimbo, 2005; Haas, 2005; Marikkar et al., 2003; Arnaud et al., 2004; Lee, Foglia, 2000a,b; Chiu, Gioielli, 2002a,b; Chiu, Gioielli, Sotero Solis, 2002; Orthoefer, 1996). As pequenas diferenças existentes prova- velmente são devidas a fatores intrínsecos às aves, tais como idade, sexo, raça, clima, tipo de alimentação e de tecido adiposo analisado (Chiu, Gioielli, Sotero Solis, 2002; Chiu, Gioielli, 2002b; Vizcarrondo, Padilla, Martín, 1998; Stauffer, 1996).

Os resultados mostraram que a gordura de frango e a oleína apresentaram similaridade na composição em ácidos graxos, principalmente para os ácidos oléico $(43,4 \% \mathrm{e}$ $43,8 \%)$, palmítico $(24,7 \%$ e $24,5 \%)$ e linoléico $(17,2 \%$ e $18,6 \%$ ). Essa composição possibilita a aplicação da gordura de frango e de sua oleína na síntese de lipídios estruturados para serem utilizados na formulação de alimentos com características funcionais.

Lee, Foglia (2000b) verificaram a possibilidade da modificação da gordura de frango através da incorporação do ácido caprílico aos seus triacilgliceróis, produzindo lipídios estruturados por interesterificação.

A gordura de frango é semi-líquida à temperatura ambiente devido ao alto teor de ácidos graxos insaturados como o oléico e o linoléico, enquanto que a oleína é totalmente líquida devido a presença de menor teor de ácido esteárico $(3,5 \%)$ em relação à gordura de frango $(6,0 \%)$. Para a estearina da gordura de frango, os teores dos ácidos oléico e palmítico estiveram relativamente próximos, sendo 38,6 e $34,2 \%$, respectivamente. Por apresentar altas concentrações de ácidos graxos saturados, como palmítico $(34,2 \%)$ e esteárico $(9,1 \%)$, a estearina é sólida à temperatura ambiente. Conseqüentemente, esta fração apresentou menor índice de iodo em relação à gordura de frango e à oleína. Os índices de saponificação obtidos para a gordu-

Tabela II - Composição em ácidos graxos, índices de iodo e saponificação e pontos de amolecimento e fusão $\left({ }^{\circ} \mathrm{C}\right)$ da gordura de frango e de suas frações estearina e oleína obtidas pelo fracionamento a $20^{\circ} \mathrm{C}$

\begin{tabular}{lccc}
\hline Ácidos Graxos (\%) & Gordura de frango & Estearina & Oleína \\
\hline C14:0 mirístico & 0,6 & 0,8 & 0,8 \\
C16:0 palmítico & 24,7 & 34,2 & 24,5 \\
C16:1 palmitoléico & 7,1 & 6,3 & 7,8 \\
C18:0 esteárico & 6,0 & 9,1 & 3,5 \\
C18:1 oléico & 43,4 & 38,6 & 43,8 \\
C18:2 linoléico & 17,2 & 10,8 & 18,6 \\
C18:3 $\alpha$-linolênico & 1,0 & 0,2 & 1,0 \\
$\sum$ Saturados & 31,3 & 44,1 & 28,8 \\
$\sum$ Monoinsaturados & 50,5 & 44,9 & 51,6 \\
$\sum$ Poliinsaturados & 18,2 & 11,0 & 19,6 \\
\hline Indice de Iodo $(\mathrm{g}$ iodo/ $100 \mathrm{~g})$ & 76 & 59 & 80 \\
Índice de Saponificação $(\mathrm{mg} \mathrm{KOH} / \mathrm{g})$ & 196 & 198 & 197 \\
\hline Ponto de amolecimento $\left({ }^{\circ} \mathrm{C}\right)$ & 31,8 & 44,1 & 17,0 \\
Ponto de fusão $\left({ }^{\circ} \mathrm{C}\right)$ & 34,2 & 47,0 & 19,0 \\
\hline
\end{tabular}


ra de frango, sua estearina e oleína foram próximos $(196,4$, $197,9,196,6$, respectivamente), porque a massa molar média dos ácidos graxos nestas três gorduras é praticamente a mesma (Chiu, Gioielli, 2002a,b).

Os valores dos pontos de amolecimento e fusão da gordura de frango, estearina e oleína estão de acordo com os encontrados por Chiu, Gioielli, Sotero Solis (2002) para os mesmos materiais analisados, e compatíveis com os resultados de Haas (2005) e Bimbo (2005) para o ponto de fusão da gordura de frango, que se apresentou dentro da faixa de temperatura de 28 a $35^{\circ} \mathrm{C}$.

A gordura de frango apresenta elevado potencial em termos nutricionais em relação às outras gorduras animais, em vista da proporção recomendável de ácidos graxos saturados, monoinsaturados e poliinsaturados, normalmente da ordem de $32 / 45 / 23$, e razão entre os ácidos alinolênico e linoléico próxima da recomendação de 0,166 (Graille, Pina, 1999).

\section{Textura}

Os resultados da consistência das amostras estão apresentados na Figura 2. A gordura de frango e sua oleína apresentaram consistência somente até $20^{\circ} \mathrm{C}$ e $15^{\circ} \mathrm{C}$, respectivamente. Este resultado está de acordo com os dados obtidos por Chiu, Gioielli (2002a) e Chiu, Gioielli, Sotero
Solis (2002). A gordura de frango apresentou-se líquida ou semi-líquida à temperatura ambiente, enquanto que a oleína apresentou-se líquida. Conseqüentemente, pode ser usada na preparação de bolos, em frituras e para melhorar a consistência de cremes cosméticos (Chiu, Gioielli, 2002a; Chiu, Gioielli, Sotero Solis, 2002).

A estearina apresentou dureza até $40{ }^{\circ} \mathrm{C}$, em virtude de seu elevado teor em ácidos graxos saturados (Chiu, Gioielli, Sotero Solis 2002; Chiu, Gioielli, 2002a). Os ácidos graxos saturados de cadeia longa influenciam fortemente o conteúdo de gordura sólida e a consistência dos lipídios, devido ao seu elevado ponto de fusão, que varia de 63 a $70^{\circ} \mathrm{C}$ (Chiu, Gioielli, 2002a,b; Larsson, Quinn, 1994). A estearina pode ser utilizada para fabricação de shortenings para formulação de margarinas e produtos de panificação.

Produtos gordurosos com "yield value" na faixa de 200 a $800 \mathrm{gf} / \mathrm{cm}^{2}$ são os mais satisfatórios sob o ponto de vista de espalhabilidade. Contudo, na faixa de 800 a $1000 \mathrm{gf} / \mathrm{cm}^{2}$ a gordura é considerada dura, mas satisfatoriamente espalhável, de 1000 a $1500 \mathrm{gf} / \mathrm{cm}^{2}$ é muito dura e no limite de espalhabilidade, enquanto que acima de $1500 \mathrm{gf} / \mathrm{cm}^{2}$ é extremamente dura (Haighton, 1959). A gordura de frango e sua oleína apresentaram consistência na faixa de 200 a $800 \mathrm{gf} / \mathrm{cm}^{2}$, evidenciando que podem ser adequadas para a formulação de margarinas. A estearina de

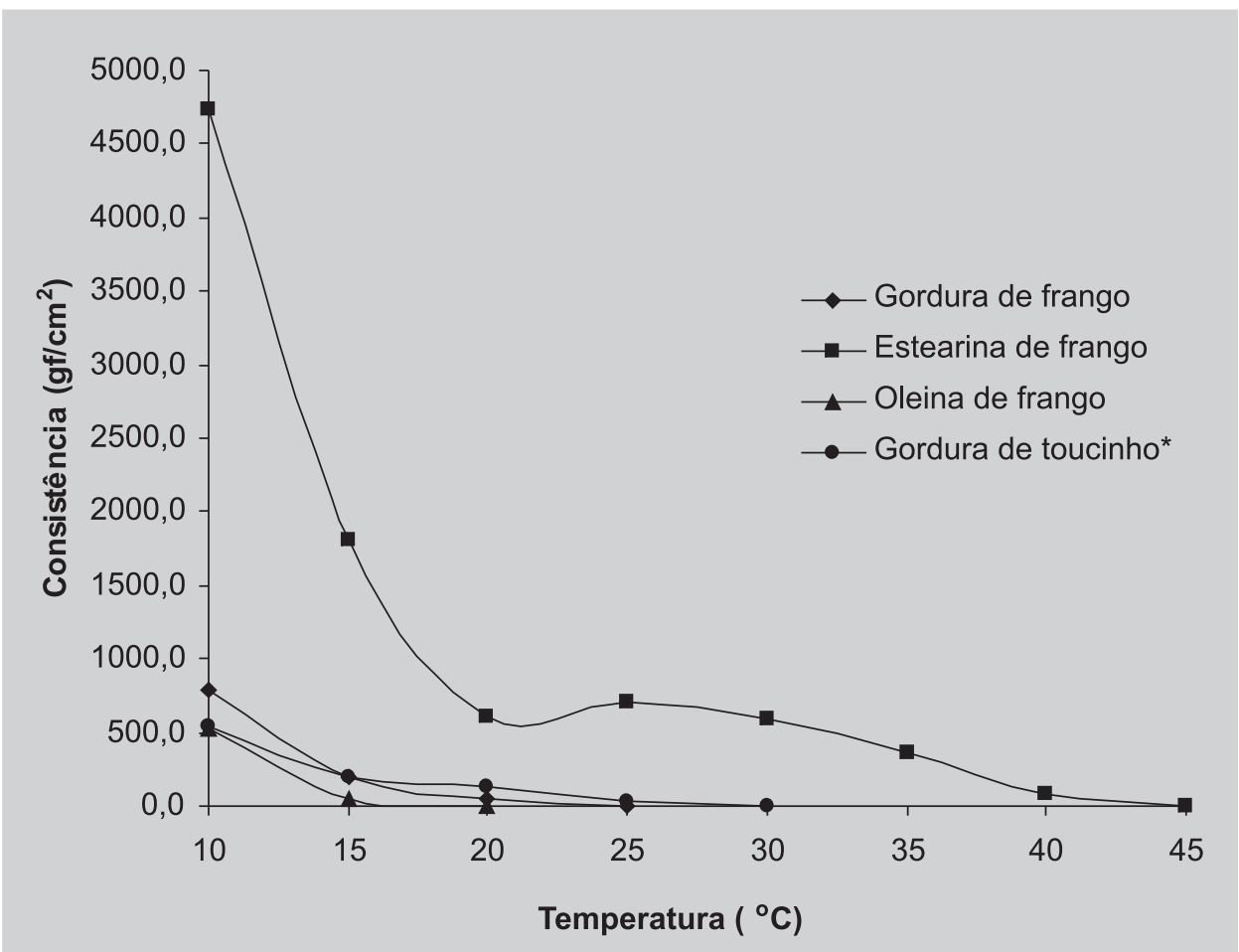

FIGURA 2 - Consistência em função da temperatura para a gordura de frango, sua estearina e oleína comparadas com a gordura de toucinho.

*Chiu, Gioielli, 2002a 
frango é classificada como muito dura à temperatura de 10 ${ }^{\circ} \mathrm{C}$. De acordo com Chiu, Gioielli, Sotero Solis (2002) e Arciszewski (1996) o efeito de óleos e gorduras na maciez de produtos gordurosos e de panificação é relevante. Em produtos como margarinas, por exemplo, a textura é um parâmetro muito importante, pois estes produtos precisam ter boas propriedades de espalhabilidade sob refrigeração e não liberar óleo quando expostos à temperatura ambiente (Chiu, Gioielli, 2002a,b; D'Agostini, Ferraz, Gioielli, 2000; Deman, Deman, Blackman, 1995). Pelo fato de apresentar maior consistência a $25{ }^{\circ} \mathrm{C}$ do que a $20{ }^{\circ} \mathrm{C}$ (Figura 2), é possível que a estearina de frango tenha sofrido recristalização a esta temperatura. Isso pode ter ocorrido devido à fusão de parte da gordura seguida por recristalização, ocasionando elevação no valor da consistência a $25{ }^{\circ} \mathrm{C}$ (Chiu, Gioielli, 2002a).

Valores de "yield value" em margarinas comerciais produzidas com óleo de soja hidrogenado ou com misturas de óleos líquidos e óleos hidrogenados apresentaram valores de $200 \mathrm{gf} / \mathrm{cm}^{2}$ para produtos macios e até $2800 \mathrm{gf} / \mathrm{cm}^{2}$ para produtos mais duros (List et al., 1995).

À temperatura de $10^{\circ} \mathrm{C}$ a consistência da gordura de frango foi superior à da gordura de toucinho (Figura 2). Contudo, com o aumento da temperatura, a gordura de frango apresentou queda brusca na consistência quando comparada à gordura de toucinho, cuja redução na consistência foi linear. Isso provavelmente ocorreu devido ao fato de a gordura de toucinho apresentar grande quantidade de triacilgliceróis do tipo ISI $(63,8 \%)$, em decorrência da preferência do ácido palmítico pela posição $s n-2$ (Chiu, 2001).

\section{Conteúdo de gordura sólida}

Os resultados do conteúdo de gordura sólida das amostras em função da temperatura estão apresentados na Figura 3, representando a média de duas determinações. Os resultados das curvas de sólidos demonstraram que as amostras apresentam perfis distintos, possibilitando obter misturas que cobrem faixas variadas de conteúdo de gordura sólida em função da temperatura (Rodrigues, Gioielli, Anton, 2003; Gamboa, Gioielli, 2003a,b; Chiu, Gioielli, 2002b; D'Agostini, et. al, 2001).

Gomes, De Felice, Catalano (1983) e Viau, Gandemer (1991) citaram que a baixa quantidade de triacilgliceróis saturados $(<3 \%)$ é responsável pelo baixo teor de gordura sólida à temperatura ambiente (3-10\% a $20^{\circ} \mathrm{C}$ ) da gordura de frango. Esse fato está associado à consistência semi-sólida desta gordura à temperatura ambiente. A estearina de frango apresentou perfil de sólidos apropriado à fabricação de margarinas para aplicação em pastelaria e massas folhadas, e gorduras para bolos e sor- vetes. Dentro da faixa de temperatura de 10 a $15^{\circ} \mathrm{C}$ a oleína de frango apresentou teor de sólidos compreendido de 13,1 a 4,5\%, podendo ser utilizada para produtos panificados e biscoitos em geral que não requeiram mais de $6 \%$ de lipídios na formulação (Stauffer, 2005; Esteller, 2004; Chiu, Gioielli, 2002a,b; Chiu, Gioielli, Sotero Solis, 2002; Stauffer, 1996) (Figura 3).

Como a consistência de gorduras é influenciada pelo conteúdo de gordura sólida do material (Chiu, Gioielli, 2002a,b; Deman, Beers, 1988), foi efetuada a relação entre essas duas propriedades, por regressão linear simples, apresentada na Tabela III. A equação da reta correspondente é a seguinte:

$y=a+b^{*} x$

Onde:

$y=$ conteúdo de gordura sólida (\%);

$\mathrm{a}=$ coeficiente linear

$\mathrm{b}=$ coeficiente angular

$\mathrm{x}=$ consistência $\left(\mathrm{gf} / \mathrm{cm}^{2}\right)$

Os resultados da Tabela 3 demonstraram que houve relação linear significativa a $p<0,05$. O coeficiente linear da reta representa o conteúdo de gordura sólida das amostras de gordura de frango, das suas estearina e oleína quando a consistência é igual a zero, apresentando valores de 2,2 a $10,4 \%$. Isto mostra que, quando o teor de sólidos na gordura é inferior a $10 \%$, o material apresenta-se como um líquido viscoso, ao invés de se comportar como uma gordura plástica (Larsson, 1994).

TABELA III - Coeficientes de regressão linear simples e coeficientes de correlação para conteúdo de gordura sólida e consistência.

\begin{tabular}{lccc}
\hline Amostras & \multicolumn{3}{c}{ Coeficientes } \\
& $\mathrm{a}$ & $\mathrm{b}$ & $\mathrm{r}$ \\
\hline Gordura de frango & 5,3 & 0,02 & 0,919 \\
Estearina & 10,4 & 0,01 & 0,890 \\
Oleína & 2,2 & 0,02 & 0,978 \\
\hline
\end{tabular}

\section{Composição em triacilgliceróis}

A Tabela IV mostra a composição em triacilgliceróis da gordura de frango e de sua estearina, variando de 48 a 54 átomos de carbono. A estearina de frango apresentou $38,4 \%$ de triacilgliceróis com 50 átomos de carbono e $16,0 \%$ com 48 átomos de carbono, indicando que esta fra- 


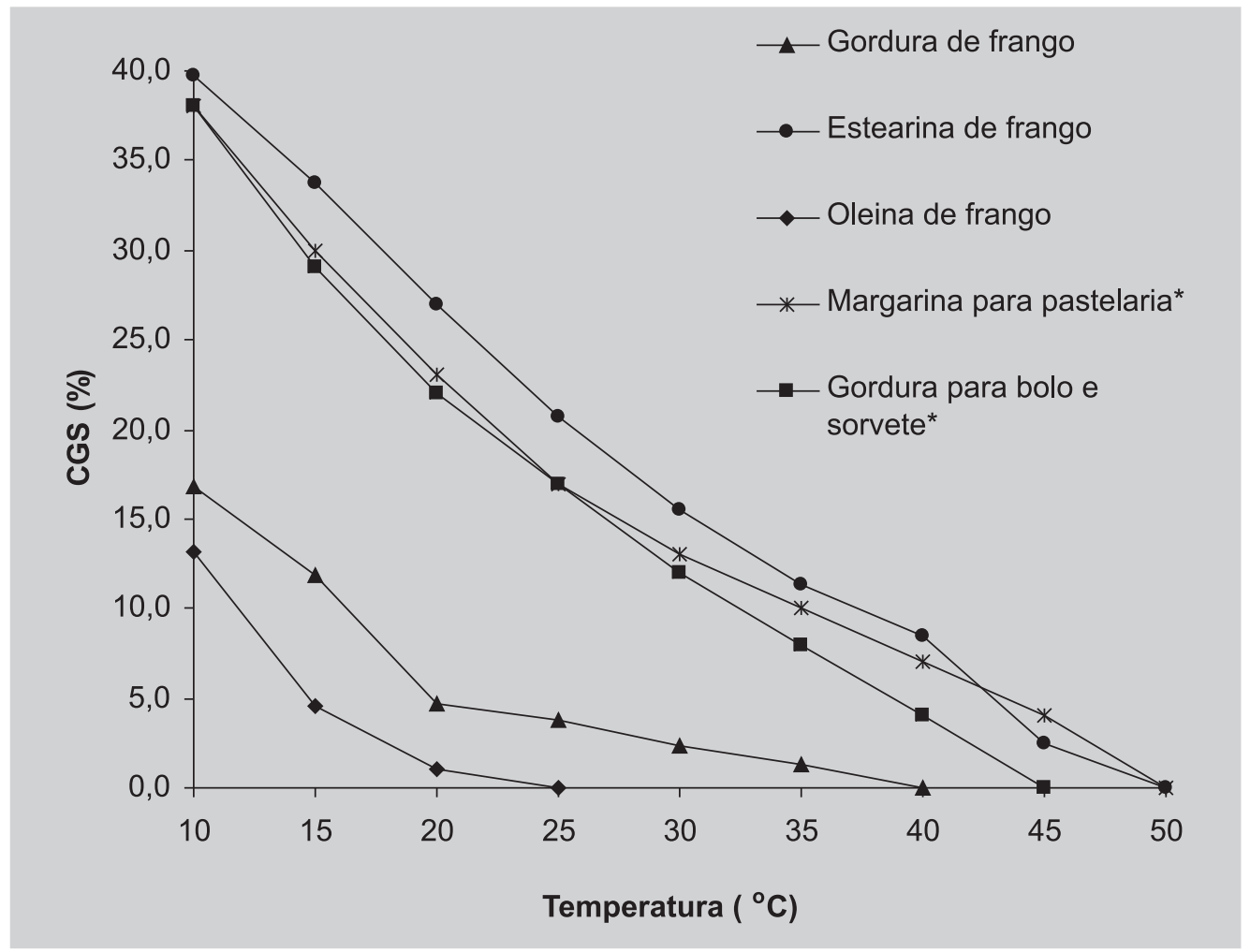

FIGURA 3 - Conteúdo de gordura sólida em função da temperatura para a gordura de frango, sua estearina e oleína em comparação com outras gorduras utilizadas na indústria de alimentos.

*Stauffer, 2005,1996.

TABELA IV - Composição em triacilgliceróis quanto ao número de carbonos da gordura de frango e sua estearina

\begin{tabular}{ccc}
\hline $\begin{array}{c}\text { Número de } \\
\text { Carbonos }\end{array}$ & $\begin{array}{c}\text { Gordura de } \\
\text { frango (\%) }\end{array}$ & $\begin{array}{c}\text { Estearina de } \\
\text { frango }(\%)\end{array}$ \\
\hline 48 & 7,3 & 16,0 \\
50 & 32,2 & 38,4 \\
52 & 46,2 & 37,7 \\
54 & 14,3 & 7,9 \\
\hline
\end{tabular}

ção apresentou predominância de triacilgliceróis dissaturados e trissaturados, compostos em grande parte por ácido palmítico, contribuindo para os elevados pontos de amolecimento e de fusão, teor de sólidos e consistência (Tabela II e Figuras 2 e 3). Por outro lado, a gordura de frango apresentou 46,2\% de triacilgliceróis com 52 átomos de carbono e apenas 7,3\% com 48 átomos de carbono, indicando que esta gordura apresentou predominância de triacilgliceróis diinsaturados, contribuindo para uma consistência semi-sólida à temperatura ambiente, com teor de sólidos e consistência intermediários entre sua fração sólida (estearina) e líquida (oleína) (Figura 2).

\section{Análise Térmica}

A Figura 4 mostra as curvas de fusão obtidas por DSC e a Tabela V apresenta os parâmetros de fusão da gordura de frango e de suas frações oleína e estearina. É possível observar os distintos comportamentos térmicos destas três gorduras em face da composição diferente em ácidos graxos e triacilgliceróis que as compõem.

Os valores de temperatura "T onset" (temperatura correspondente ao ponto onde a curva começa a se desviar da linha de base, ou seja, temperatura inicial de fusão) e "T end" (temperatura correspondente ao ponto onde a curva começa a retornar à linha de base, ou seja, temperatura final de fusão), "T pico" (temperatura onde o efeito é máximo em termos de energia ou temperatura, onde a fusão é máxima) e " $\Delta \mathrm{H}_{\text {cal }}$ " (entalpia de fusão correspondente ao calor latente, isto é, à energia que deve ser fornecida à amostra para que ocorra fusão completa dos cristais) (Nassu, 1994), obtidos através das curvas de fusão de DSC estão apresentados na Tabela V. Conforme observado nesta Tabela, a gordura de frango apresentou menor temperatura "onset" que suas frações. Em relação à temperatura de pico, foram observados dois picos de fusão distintos para a gordura de frango e para a sua estearina, ao passo que a 


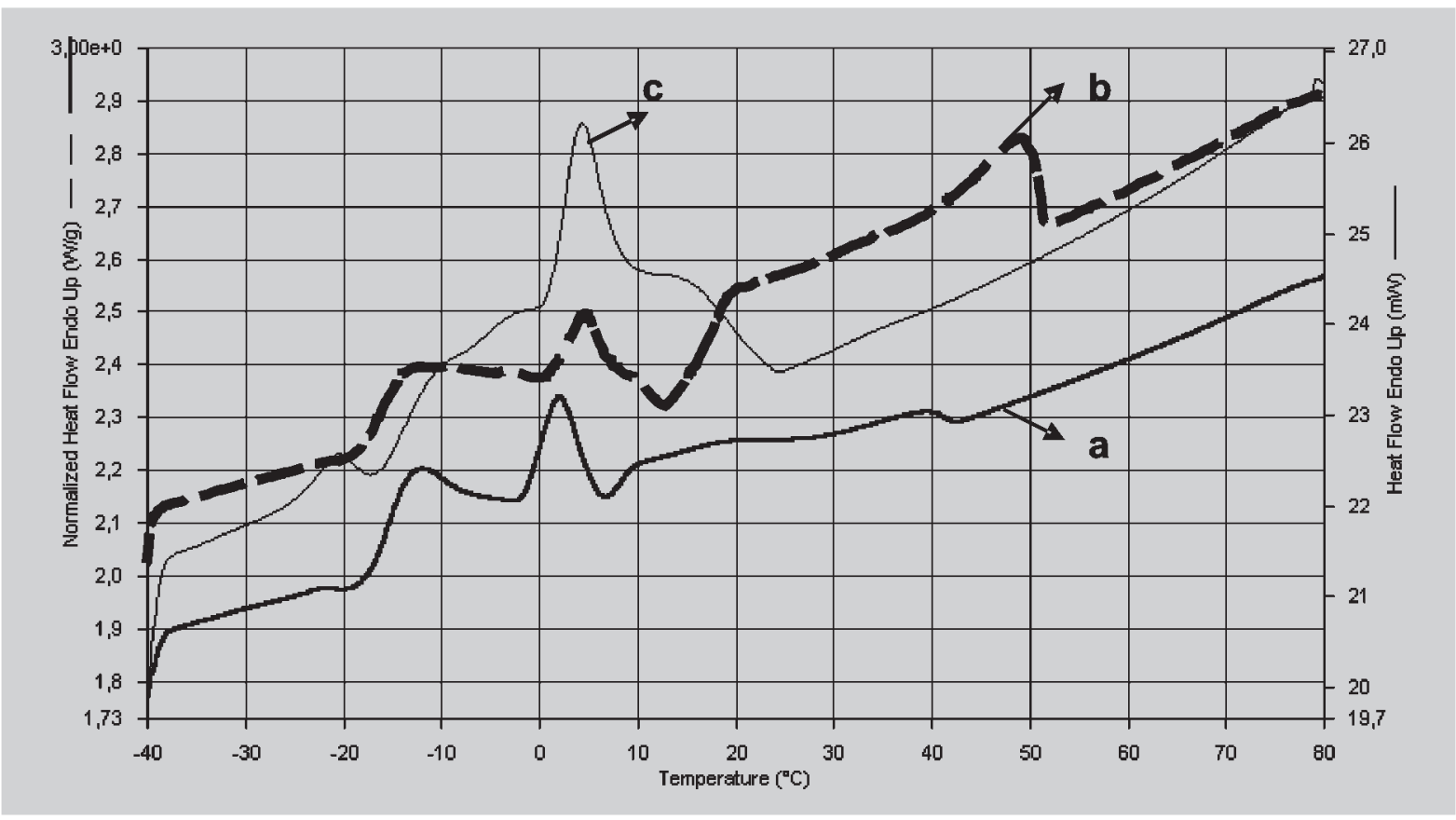

FIGURA 4 - Curvas de fusão obtidas pela técnica de DSC da gordura de frango (a) e de suas frações estearina (b) e oleína (c).

oleína apresentou apenas um pico de fusão. Considerando a temperatura final de fusão, a estearina apresentou maior valor para este parâmetro, devido à sua elevada proporção de triacilgliceróis dissaturados e trissaturados. Finalmente, avaliando a entalpia de fusão da gordura de frango e de sua oleína, observa-se similaridade entre estas gorduras devido ao elevado rendimento da fração líquida no processo de fracionamento $(83,5 \%)$. A menor entalpia de fusão observada para a estearina deveu-se à recristalização ocorrida na faixa de temperatura de 8 a $19^{\circ} \mathrm{C}$, caracterizando um efeito exotérmico, ou seja, com liberação de energia.

\section{Análise Térmica da Gordura de Frango}

Foram detectadas três faixas de fusão para a gordura de frango (Figura 5), caracterizadas pelo retorno da curva de fusão à linha de base:
A faixa inicial variou de -35 a $-20{ }^{\circ} \mathrm{C}$ (a) e correspondeu à fusão de triacilgliceróis triinsaturados como $\mathrm{OOO}=-32{ }^{\circ} \mathrm{C}$ e $\mathrm{LLL}=-45^{\circ} \mathrm{C}$ na forma $\alpha$ (Bockisch, 1998).

- A faixa intermediária variou de -20 a $8{ }^{\circ} \mathrm{C}$ (b) e correspondeu à fusão de triacilgliceróis triinsaturados e diinsaturados do tipo $\mathrm{OOO}=5,6^{\circ} \mathrm{C}, \mathrm{POL}=$ $-2,8^{\circ} \mathrm{C}$ e $\mathrm{LOS}=6,1^{\circ} \mathrm{C}$ na forma $\beta$ (Bockisch, 1998).

- $\quad$ Finalmente, a última faixa variou de 8 a $42,4{ }^{\circ} \mathrm{C}$ (c) e correspondeu aos triacilgliceróis trissaturados e dissaturados $\mathrm{PPP}=56,1^{\circ} \mathrm{C}, \mathrm{PPS}=60^{\circ} \mathrm{C}, \mathrm{PPO}=35^{\circ} \mathrm{C}$, $\mathrm{PSO}=37,8^{\circ} \mathrm{C}, \mathrm{LPP}=27,2^{\circ} \mathrm{C}$ e $\mathrm{SOO}=22,8^{\circ} \mathrm{C}$ na forma $\beta$ (O’Brien, 1998; Bockisch, 1998).

Os resultados obtidos foram muito semelhantes aos encontrados por Arnaud et al. (2004), que analisaram gordura de frango utilizando o mesmo método.

TABELA V - Dados provenientes das curvas de fusão obtidas por DSC para a gordura de frango e suas frações oleína e estearina

\begin{tabular}{lccccc}
\hline Amostras & $\begin{array}{c}\text { Temperatura } \\
\text { "onset" }\left({ }^{\circ} \mathrm{C}\right)\end{array}$ & \multicolumn{2}{c}{$\begin{array}{c}\text { Temperatura } \\
\text { de pico }\left({ }^{\circ} \mathrm{C}\right)\end{array}$} & $\begin{array}{c}\text { Temperatura } \\
\text { final de fusão }\left({ }^{\circ} \mathrm{C}\right)\end{array}$ & $\begin{array}{c}\text { Entalpia de } \\
\text { fusão }(\mathrm{J} / \mathrm{g})\end{array}$ \\
\hline Gordura de frango & & $(1)$ & $(2)$ & & \\
Estearina & $-36,0$ & 2,1 & 24,7 & 42,4 & 59,66 \\
Oleína & $-20,5$ & 3,9 & 48,9 & 51,8 & 53,23 \\
\hline
\end{tabular}




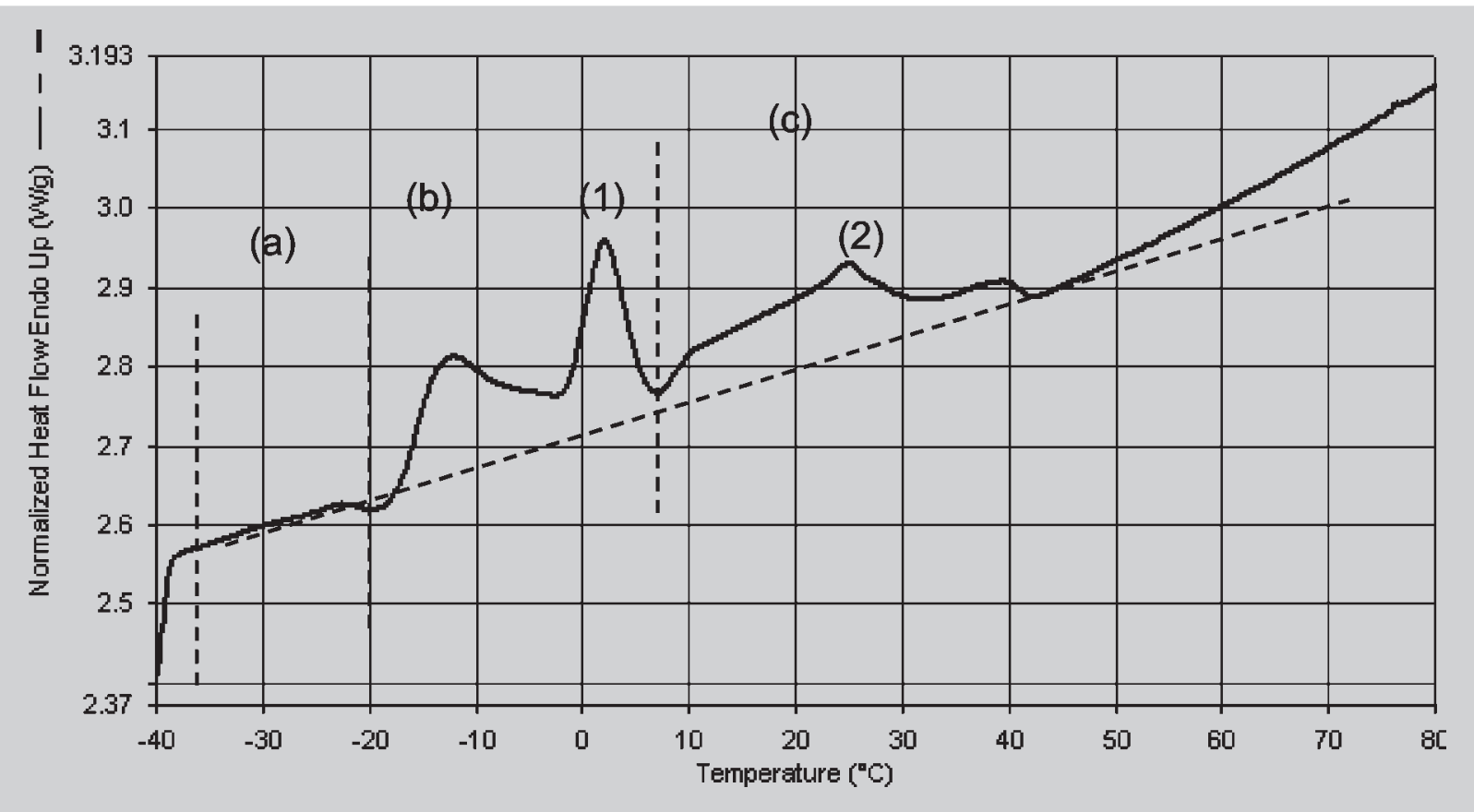

FIGURA 5 - Curvas de fusão da gordura de frango obtida pela técnica de DSC.

\section{Análise Térmica da Estearina}

A estearina de frango apresentou parte da curva de fusão abaixo da linha de base. Esta porção esteve situada na faixa de temperatura de 8 a $19^{\circ} \mathrm{C}$ (Figura 6).

Esta característica foi observada por Grimaldi et al.
(2001) em estudo realizado com óleo de palma natural e interesterificado. De acordo com Grimaldi et al. (2001) e Nassu, Gonçalves (1999) a porção da curva abaixo da linha de base corresponde a um efeito exotérmico, ou seja, à recristalização de uma parcela da gordura seguida de sua fusão junto da fração sólida do óleo em estudo. De forma

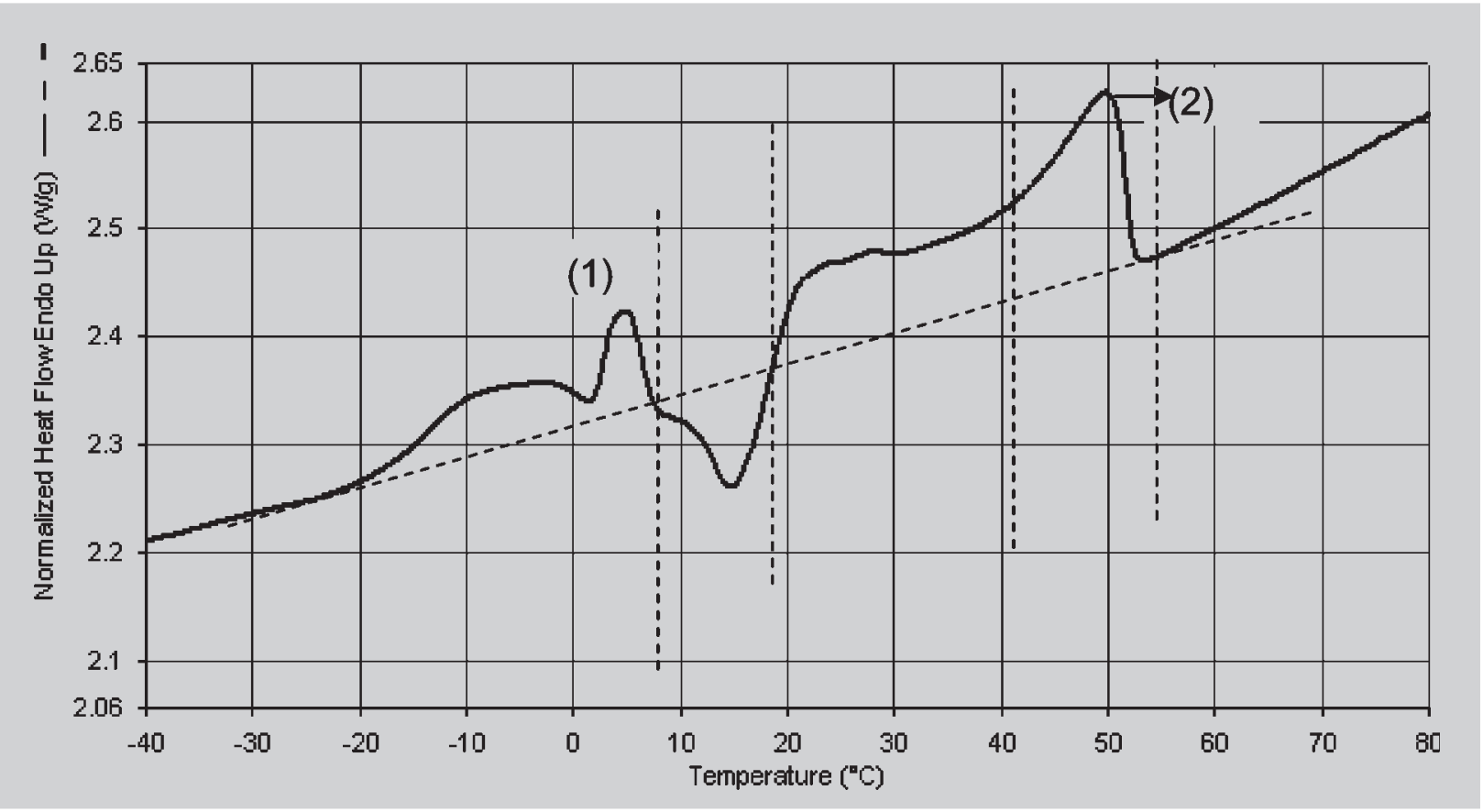

FIGURA 6 - Curvas de fusão da estearina de frango obtida pela técnica de DSC. 


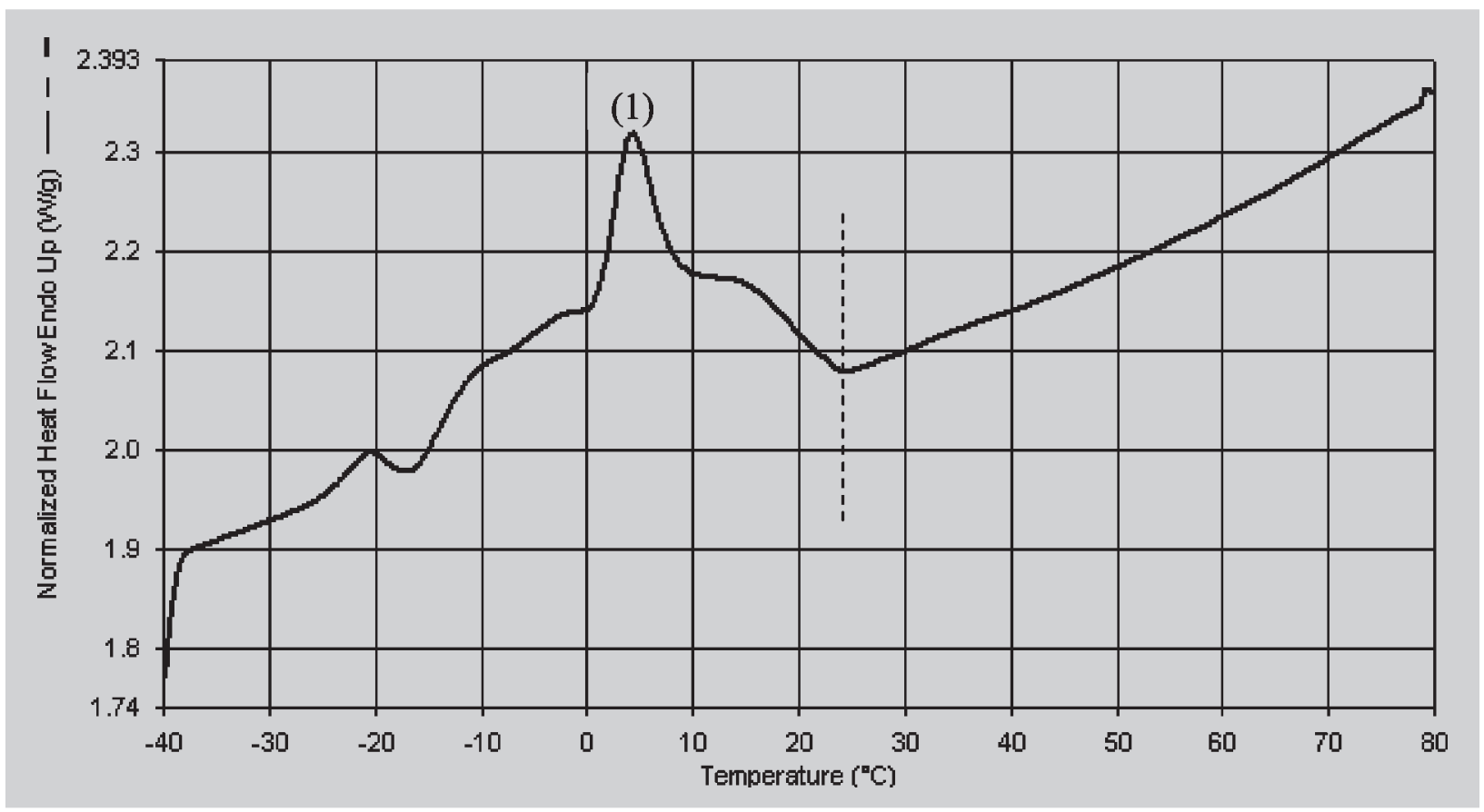

FIGURA 7 - Curvas de fusão da oleína de frango obtida pela técnica de DSC.

semelhante, neste estudo, o efeito exotérmico foi verificado com a estearina de frango. Esta recristalização também foi observada para a propriedade de consistência, conforme pode ser observado na Figura 2, ocorrida na temperatura de $25{ }^{\circ} \mathrm{C}$. Pode-se inferir que na faixa de 40 a $55^{\circ} \mathrm{C}$ houve predominância de triacilgliceróis trissaturados e dissaturados (Figura 6).

\section{Análise Térmica da Oleína}

A oleína apresentou curva de fusão semelhante à da gordura de frango devido ao seu elevado rendimento no processo de fracionamento $(83,5 \%)$. Nesta fração lipídica houve predominância de triacilgliceróis triinsaturados e diinsaturados, e, conseqüentemente, menores teores de trissaturados e dissaturados que a gordura de frango. Dessa forma, seus pontos de amolecimento e de fusão foram menores (Tabela II), apresentando fusão completa dos cristais aproximadamente à temperatura de $23{ }^{\circ} \mathrm{C}$ (Figura 7).

\section{CONCLUSÕES}

Este estudo evidenciou os benefícios do uso do fracionamento a seco para melhorar a qualidade tecnológica da gordura de frango. Foi obtida estearina sólida à temperatura ambiente com características físicas semelhantes às de gorduras utilizadas pela indústria de alimentos. A estearina de frango pode ser utilizada como componente na fabricação de gorduras para aplicação em margarinas para pastelaria, massas folhadas e gorduras para bolos e sorvetes.

O alto rendimento da oleína da gordura abdominal de frango sugere a possibilidade de aplicação desta fração como óleo para frituras e produtos panificados e biscoitos em geral, que não requeiram mais de $6 \%$ de lipídios na formulação, bem como para a síntese de lipídios estruturados.

\section{ABSTRACT}

\section{Dry fractionation of chicken fat in pilot scale}

The world consume of chicken meat was 57.8 million tons in 2006, according to the United States Department of Agriculture (USDA) estimative. The abdominal chicken fat corresponds to approximately $2.5 \%$ of the weight of the slaughtered chicken. The objectives of this study were to fractionate the abdominal chicken fat and to evaluate its fractions regarding the physical and chemical properties. Chicken fat was processed by dry fractionation to obtain a solid fraction at ambient temperature. Crystallization and separation were performed using industrial-type procedures. Softening point, consistency, solid fat content, fatty acid and triglyceride compositions, iodine and saponification values, and the thermal behavior of the samples were evaluated. Results showed that chicken fat had $68.7 \%$ of unsaturated fatty acids. Among these, monounsaturated fatty acids, such as oleic acid, are considered desirable in regard to decrease the risk of 
cardiovascular diseases. The higher softening point of the stearin was due the greatest levels of saturated fatty acids (mainly palmitic and stearic acids). Chicken fat and olein at $10^{\circ} \mathrm{C}$ were plastic and spreadable. The high olein yield suggests that this fraction can be used as frying oil and in the synthesis of structured lipids. The stearin can be applied as component in the fat manufacturing, in puffpastry margarines and also in cake and icing shortening.

UNITERMS: Abdominal chicken fat. Stearin. Olein. Dry fractionation. Foods.

\section{AGRADECIMENTOS}

À Fundação de Amparo à Pesquisa do Estado de São Paulo - FAPESP, à Fundação Coordenação de Aperfeiçoamento de Pessoal de Nível Superior - CAPES e ao Conselho Nacional de Desenvolvimento Científico e Tecnológico - CNPq, pelo auxílio financeiro e pelas bolsas concedidas aos autores.

\section{REFERÊNCIAS BIBLIOGRÁFICAS}

ABEF. ASSOCIAÇÃO BRASILEIRA DOS EXPORTADORES DE FRANGO. Estatísticas: produção mensal brasileira de aves, histórico do consumo brasileiro de carne de frango, exportações mensais brasileiras de frango. Disponível em: $<$ http:// www.abef.com.br>. Acesso em: 22 set. 2006.

ABEF. ASSOCIAÇÃO BRASILEIRA DOS EXPORTADORES DE FRANGO. Relatório Anual 2005: produção mundial, consumo mundial. Disponível em: $<$ http://www.abef.com.br>. Acesso em: 22 set. 2006.

AMERICAN OIL CHEMISTS' SOCIETY. Official methods and recommended practices of the AOCS. 5.ed. Champaign, 1998.

APA. ASSOCIAÇÃO PAULISTA DE AVICULTURA. Estatísticas: frangos, produção nacional e mundial. Disponível em: $<$ http://www.apa.com.br $>$. Acesso em: 22 set. 2006.

ARCISZEWSKI, H. Funcionalidade de gorduras, redução em produtos de panificação. Óleos \& Grãos, n.28, p.25-29, 1996.

ARNAUD, E.; RELKIN, P.; PINA, M.; COLLIGNAN, A. Characterisation of chicken fat dry fractionation at the pilot scale. Eur. J. Sci. Technol., v.106, n.9, p.591-598, 2004.
BIMBO, A. P. Rendering. In: Shahidi, F., (Ed.). Bailey's industrial oil and fat products. 6. ed. New York: Wiley, 2005. v.6, p.57-102.

BOCKISCH, M. Modification of fats and oils. In: Bockisch, M., (Ed). Fats and oils handbook. Champaign: AOCS PRESS, 1998. p. 446-612.

CHIU, M. C. Caracterização, fracionamento e aproveitamento da gordura abdominal de frango. São Paulo, 2001. 113p. [Dissertação de Mestrado. Faculdade de Ciências Farmacêuticas. Universidade de São Paulo].

CHIU, M. C.; GIOIELLI, L. A.; SOTERO SOLIS, V. E. Fraccionamiento de la grasa abdominal de pollo. Grasas Aceites, v. 53, n. 3, p. 298-303, 2002.

CHIU, M. C.; GIOIELLI, L. A. Consistência da gordura abdominal de frango, de suas estearinas e de suas misturas binárias com toucinho. Rev. Bras. Cienc. Farm., v.38, n.1, p.95-105, 2002a.

CHIU, M. C.; GIOIELLI, L. A. Conteúdo de gordura sólida da gordura abdominal de frango, de suas estearinas e de suas misturas binárias com toucinho. Cienc. Tecnol. Aliment., v.22, n.2, p.151-157, 2002 b.

D’AGOSTINI, D.; FERRAZ, R. C.; GIOIELLI, L. A. Consistência de misturas binárias e ternárias de gorduras de palma, palmiste e triacilgliceróis de cadeia média. Rev. Bras. Cienc. Farm., v. 36, n. 1, p. 147-155, 2000.

D’AGOSTINI, D.; FERRAZ, R. C.; SOTERO SOLIS, V. E.; GIOIELLI, L.A. Contenido de grasa sólida de las mezclas binarias y ternarias de aceite de palma, aceite de semilla de palma y triacilgliceroles de cadena media. Alimentaria, v. 38, n. 324, p.47-53, 2001.

DEMAN, J. M., BEERS, A. M. Fat crystal networks: structure and rheological properties. J. Texture Stud., v.18, n.4, p.303-318, 1988 .

DEMAN, L.; DEMAN, J. M.; BLACKMAN, B. Effect of tempering on the texture and polymorphic behaviour of margarine fats. Fat Sci. Technol., v.97, n.2, p.55-60, 1995.

ESTELLER, M. S. Fabricação de pães com reduzido teor calórico e modificações reológicas ocorridas durante o armazenamento. São Paulo, 2004, 226p [Dissertação de Mestrado. Faculdade de Ciências Farmacêuticas. Universidade de São Paulo]. 
GAMBOA, O. W. D.; GIOIELLI, L. A. Consistencia de lípidos estructurados a partir de aceite de pescado y grasa de palmiste. Grasas Aceites, v.54, n.2,p.122 - 129, 2003 a.

GAMBOA, O. W. D.; GIOIELLI, L.A. Lípidos estructurados obtenidos por interesterificación química y enzimática a partir de aceite de pescado y grasa de semilla de palma. Grasas Aceites, v.54, n.2, p.161 - 168, 2003 b.

GIBON, V:; TIRTIAUX, A. Latest trends in dry fractionation. Lipid Technol., v.14, n.2, p.33-36, 2002.

GOMES, T.; DE FELICE, M.; CATALANO, M. Il grasso di pollame. Profilo di fusione per NMR e composizione trigliceridica di frazioni fluide e concrete. Riv. Ital. Sostanze Grasse, v.60, p.569-573, 1983.

GRAILLE, J.; PINA, M. L'huile de palme, sa place dans l'alimentation humaine. Plantation Recherche Développement., v.6, n.6, p.85-90, 1999.

GRIMALDI, R.; GONÇALVES, L.A. G.; GIOIELLI, L. A.; SIMÕES, I. S. Interactions in interesterified palm and palm kernel oils mixtures. II - Microscopy and differential scanning calorimetry. Grasas Aceites, v.52, n.6, p.363368, 2001.

HAAS, M. J. Animals fats. In: Shahidi, F., (Ed.). Bailey's industrial oil and fat products. 6. ed. New York: Wiley, 2005. v.1, p.161-212.

HAIGHTON, A. J. The measurement of the hardness of margarine and fats with cone penetrometers. J. Am. Oil Chem. Soc., v.36, n.8, p.345-348, 1959.

HARTMAN. L.; LAGO, R. C. A. Rapid preparation of fatty acid methyl esters from lipids. Lab. Pract., London, v.22, p.475-476, 494, 1973.

LARSSON, K. Lipids: molecular organization, physical functions and technical applications. Dundee: The Oily Press, 1994. p.7-45.

LARSSON, K.; QUINN, P. J. Physical properties: structural and physical characteristics. In: GUNSTONE, F. D., HARTWOOD, J. L., PADLEY, F. B., (Eds.). The lipid handbook. 2 ed. London: Chapman and Hall, 1994. p.401-460.
LEE K. T.; FOGLIA T. A. Fractionation of chicken fat triacylglycerols: Synthesis of structured lipids with immobilized lipases. J. Food Sci., v.65, n.5, p.826-831, 2000a.

LEE K. T.; FOGLIA T. A. Synthesis, purification, and characterization of structured lipids produced from chicken fat. J. Am. Oil Chem. Soc., v.77, n.10, p.10271034, 2000b.

LIST, G. R.; MOUNTS, T. L.; ORTHOEFER, F.; NEFF, W. E. Margarine and shortening oils by interesterification of liquid and trisaturated triglycerides. J. Am. Oil Chem. Soc., v.72, n.3, p.379-382, 1995.

MARIKKAR, J. M. N.; GHAZALI, H. M.; LONG, K., LAI, O. M. Lard uptake and its detection in selected food products deep-fried in lard. Food Res. Int., v.36, n. 9-10, p.1047-1060, 2003.

NASSU, R. T. Estudo do comportamento térmico de óleo e gorduras por calorimetria de varredura diferencial (DSC). Campinas, 1994. 93p. [Dissertação de Mestrado. Faculdade de Engenharia de Alimentos. Universidade Estadual de Campinas].

NASSU, R. T., GONÇALVES, L. A. G. Determination of melting point of vegetable oils and fats by differencial scanning calorimetry (DSC) technique. Grasas Aceites, v.50, n.1, p.16-22, 1999.

O'BRIEN, R. D. Fats and oils processing. In O'BRIEN, R. D., (Ed.). Fats and oils: Formulating and processing for applications. Lancaster: Technomic Publishing Co., Inc., 1998. p. 47-175.

OLIVO, R. Atualidades na qualidade da carne de aves. Rev. Nac. Carne, São Paulo, 2004. Disponível em: $<$ http:// w w w.dipe mar.com.br/carne/331/ material_artigo_carne.htm>. Acesso em: 04 out. 2004.

ORTHOEFER, F. T. Vegetable oils. In: Hui, Y. H., (Ed.). Bailey's industrial oil and fat products. 5. ed. New York: Wiley, 1996. v.1, p.19-44.

RODRIGUES, J. N.; GIOIELLI, L. A.; ANTON, C. Propriedades físicas de lipídios estruturados obtidos de misturas de gordura do leite e óleo de milho. Ciênc. Tecnol. Aliment., v.23, n.2, p.226 - 233, 2003. 
RODRIGUES J. N.; MANCINI FILHO, J.; TORRES,R. P.;

GIOIELLI, L. A. Caracterização físico-química de creme vegetal enriquecido com ésteres de fitosteróis. Rev. Bras. Cienc. Farm., v. 40, n. 4, p. 505-520, 2004.

STAUFFER, C. E. Fats and oils. St. Paul: Eagan Press, 1996. p.19-43.

STAUFFER, C. E. Fats and oils in bakery products. In: Shahidi, F., (Ed.). Bailey's industrial oil and fat products. 6. ed. New York: Wiley, 2005. v.4, p.207-227.
TIMMS, R. E. Fractional crystallization - the fat modification process for the $21^{\text {st }}$ century. Eur. J. Sci. Technol., v.107, n.1, p.48-57, 2005.

VIAU, M.; GANDEMER, G. Principales caractéristiques de composition des graisses de volaille. Rev. Fr. Corps Gras, v.38, n.5-6, p.171-177, 1991.

VIZCARRONDO, C. A.; DE PADILLA, F. C.; MARTÍN, E. Fatty acid composition of beef, pork, and poultry fresh cuts, and some of their processed products. Arch. Latin. Amer. Nutr., v.48, n.4, p. 354-358, 1998.

Recebido para publicação em 31 de outubro de 2006. Aceito para publicação em 03 de julho de 2007. 